\title{
A Gestão de Inovação em Empresa de Eventos na Cidade do Rio de Janeiro (Rio de Janeiro, Brasil)
}

\author{
The innovation management in Event Company in Rio de Janeiro city \\ (Rio de Janeiro, Brazil)
}

\author{
Roberto Pessoa de Queiroz Falcão (FALCÃO, R. P. de Q.) ${ }^{*}$ e \\ Saulo Barroso Rocha (ROCHA, S. B.) ${ }^{* *}$
}

\begin{abstract}
RESUMO - No estudo verificam-se as características do processo da inovação, do ponto de vista da acumulação de capacidades, e suas implicações utilizando como base de estudos a análise de uma empresa aqui denominada como Alfa, (nome fictício), que estava atuando no segmento de feiras e eventos na cidade do Rio de Janeiro (Rio de Janeiro, Brasil). A relevância deste trabalho se dá pela importância da área de eventos e sua contribuição para o turismo de negócios e eventos do Brasil. O trabalho tem como objetivo principal cotejar a literatura recente de inovação e acumulação de capacidades tecnológicas com evidências coletadas na empresa. Como objetivos intermediários deste estudo se buscou: traçar sugestões, baseadas em observação de características da inovação dentro da organização, à luz de Leonard-Barton (1998); e sugerir ações para acumulação de capacidade tecnológicas e inovação em empresas de eventos. A metodologia utilizada é qualitativa. Com base em entrevistas com gestores, observação direta e análise de documentos internos da Alfa foi possível realizar análise de conteúdo a fim de atingir o objetivo principal do trabalho. Na conclusão do artigo se descrevem recomendações aplicadas para que a empresa alcance novas fronteiras da inovação, bem como oferecer subsídios para outras empresas do setor de feiras e eventos implantarem ações inovadoras.
\end{abstract}

Palavras-chave: Turismo; Eventos; Inovação; Gestão.

ABSTRACT - In this paper is analyzed the characteristics of the innovation process, from the point of view of capability accumulation, and its implications. It was used as a basis for the analysis, a company here named as Alpha, (not its real name), which was working in the fairs and events trade in Rio de Janeiro (Rio de Janeiro, Brazil). The relevance of this work is due to the importance of the event management area and its contribution to business and events tourism in Brazil. This paper aims to collate the recent literature of innovation and accumulation of technological capabilities with

\footnotetext{
* Formação: Graduação em Agronomia pela Universidade Federal de Viçosa (UFV). Mestrado em Administração pela Escola Brasileira de Administração Pública e de Empresas (EBAPE/FGV). Atividade profissional: Professor Substituto do Departamento de Empreendedorismo e Gestão da Universidade Federal Fluminense. Endereço físico para correspondência: Rua Mario Santos Braga, S/N - Prédio do Instituto de Matemática - sala 703, Centro. CEP: 24020-140 - Niterói - Rio de Janeiro (Brasil). E-mail: robertopqfalcao@gmail.com

** Formação: Mestrado em Gestão Empresarial pela Fundação Getúlio Vargas (FGV) e Doutorado em Administração pela Escola Brasileira de Administração Pública e de Empresas (EBAPE/FGV). Atividade profissional: Analista de Sistemas, Professor Adjunto do Departamento de Empreendedorismo e Gestão da Universidade Federal Fluminense (UFF). Endereço físico para correspondência: Rua Mário Santos Braga, S/N - Prédio do Instituto de Matemática - sala 703, Centro. CEP: 24020-140 - Niterói - Rio de Janeiro (Brasil). E-mail: saulorocha@id.uff.br
} 
evidences collected in the company. The intermediate objectives of this study were: propose suggestions based on observation with innovation characteristics within the organization using Leonard-Barton (1998) contribution; and suggest actions to accumulation of technological capacity and innovation in business events. The methodology is qualitative and based on interviews with managers, direct observation and analysis of Alfa's internal documents. It was possible to accomplish a content analysis in order to achieve the main objective of the work. At the conclusion of the article, the authors present their recommendations to the company, and thus, it can reach new frontiers of innovation, as well as provide subsidies to other companies of the same sector.

Key words: Tourism; Events; Innovation; Management. 


\section{INTRODUÇÃO}

A inovação não é um fenômeno novo. Parece haver algo inerentemente humano sobre a tendência de pensar em maneiras novas e melhores de fazer as coisas e testá-las na prática. Apesar de sua importância óbvia, a inovação nem sempre recebia a atenção dos estudiosos. Por exemplo, estudiosos de mudanças econômicas focalizavam tradicionalmente em fatores como a acumulação de capital ou o funcionamento dos mercados, ao invés de inovação. Isto tem mudado nas décadas recentes. Pesquisas sobre o papel da inovação na mudança econômica e social têm proliferado nos últimos anos, particularmente no âmbito das ciências sociais (FAGERBERG; MOWERY; NELSON, 2005; CASTELLACCI, 2008), e com uma tendência para a multidisciplinaridade (DOSI, 1982, 1988, 1997; FAGERBERG; MOWERY; NELSON, 2005).

A abordagem de inovação e capacidades tecnológicas deste estudo é enfocada nos aspectos organizacionais. Neste artigo, se investiga o acúmulo das capacidades tecnológicas de uma das maiores empresas de eventos do Brasil, com sede na cidade do Rio de Janeiro, estado do Rio de Janeiro (Brasil). Por motivos de confidencialidade, neste trabalho, optou-se por ocultar a identidade da empresa objeto desta pesquisa, utilizando-se apenas o nome fictício de Alfa.

Como competência ou capacidade tecnológica, entendem-se os recursos necessários para gerar e administrar melhorias em investimentos, processos e organização da produção, produtos e equipamentos. Esses recursos são acumulados e incorporados em indivíduos (experiência e habilidades, conhecimento tácito) e sistemas organizacionais (BELL; PAVITT, 1995, 1997).

O estudo teve como objetivo principal cotejar a literatura sobre acumulação de capacidades tecnológicas com os dados e informações coletadas na empresa objeto deste estudo.

Como objetivos intermediários deste estudo se buscou: traçar sugestões, baseadas em observação de características da inovação dentro da organização Alfa, à luz de Leonard-Barton (1998); e sugerir ações para acumulação de capacidades tecnológicas e inovação em empresas de eventos. 


\section{O MERCADO DE EVENTOS NO BRASIL}

A Alfa se tornou a operação brasileira de um dos maiores grupos do setor de eventos mundiais. Com sede na França a holding proprietária de Alfa, foi responsável pela realização de 4.200 eventos em 2014 e um faturamento de 940 milhões de euros, conforme relatado pela diretoria e através de pesquisas documentais. No Brasil, no momento da pesquisa de campo, a empresa possuía a concessão de grandes espaços de eventos, no Rio de Janeiro e em São Paulo. Com escritórios no Rio de Janeiro, São Paulo, Belo Horizonte e Salvador, a Alfa estava sendo o único grupo da América Latina a trabalhar em toda cadeia da produção de eventos: da administração de espaços, construção, fornecimento de estrutura e montagem, serviços de catering, organização de exibições, produção de brand events. O grupo desembarcou no Brasil em 2006. Ao chegar, atuou nos Jogos Panamericanos de 2007 e venceu as licitações para fazer a gestão do Riocentro, do SP Expo (antigo Espaço Imigrantes) e da HSBC Arena.

Segundo dados da Associação Internacional de Congressos e Convenções (ICCA, 2014), pela sigla em inglês, o Brasil se encontrava na segunda posição do ranking das Américas, sendo o primeiro país da América Latina, e ficando abaixo apenas dos Estados Unidos da América. Ao todo, o país recebeu 291 eventos classificados como internacionais segundo os critérios da ICCA em 2014. São Paulo e Rio de Janeiro se encontravam em terceiro e quinto lugar no ranking das Américas, tendo sediado respectivamente 66 e 64 eventos internacionais.

Já segundo a União Brasileira dos Promotores de Feiras (UBRAFE, 2015), o mercado nacional das feiras de negócios movimentou cerca de R\$ 4 bilhões (PROPMARK, 2012). A atividade, além de estimular comércio, turismo e hotelaria, gerou mais de 185 mil empregos temporários (120 mil apenas em São Paulo), dentro e fora dos pavilhões de exposições. Estima-se que este número de empregos gerados em todo Brasil seja no mínimo três vezes o da cidade de São Paulo.

\section{ACUMULAÇÃO TECNOLÓGICA E INOVAÇÃO EM EVENTOS}

Os autores Bell e Figueiredo (2012) evidenciaram que muitas empresas no contexto de economias emergentes iniciavam o seu negócio a partir de tecnologias 
adquiridas de outras empresas, normalmente do exterior, sendo copiadoras ou apenas assimiladores de tecnologias. Ao iniciarem as suas atividades, estas empresas em geral não dispõem sequer das capacidades tecnológicas básicas. Para tornarem-se competitivas e aproximarem-se de empresas da 'fronteira tecnológica internacional', elas têm que se engajar em um processo de aprendizagem para construir e acumular sua capacidade tecnológica. Com base em Bell e Pavitt (1995, 1997), que trouxeram ampla definição sobre o conceito de recursos tecnológicos, Kim (1997) afirma que, nessa literatura, recursos tecnológicos são entendidos como a capacidade de utilizar os conhecimentos tecnológicos de forma eficiente para assimilar, utilizar, adaptar e mudar as tecnologias existentes, e também como a capacidade de criar novas tecnologias e desenvolver novos produtos e processos.

Normalmente, as empresas que operam no contexto de economias emergentes também apresentam desvantagens por estarem deslocadas das principais fontes internacionais de tecnologia, pesquisa e desenvolvimento, e afastadas dos principais mercados internacionais para os quais elas desejam fornecer. Localizadas em um país em desenvolvimento, essas empresas precisam construir externamente as suas redes de fornecedores e clientes a partir de suas capacidades tecnológicas.

Segundo Leonard-Barton (1998) as capacidades tecnológicas acumulam-se em quatro dimensões dentro das organizações, sendo elas evidenciadas da seguinte forma: a) os sistemas técnicos físicos, b) o conhecimento e qualificação das pessoas, c) o sistema organizacional, e d) os produtos e serviços.

Segundo Von Tunzelmann (1996) a acumulação do conhecimento nas quatro dimensões citadas acima e gerado pelo processo produtivo nas firmas, é um impulsionador da inovação. O papel das empresas segundo o autor é o de serem “instituições acumuladoras de conhecimento". Neste sentido as empresas possuem vantagens sobre os indivíduos no tocante à escala de acumulação do conhecimento.

Ainda segundo Leonard-Barton (1998), estas capacidades centrais das organizações, apesar de seu aspecto positivo e impulsionador de inovações, têm seu lado negativo, que decorre da inibição da inovação, aqui chamado de rigidez essencial ou core rigidities. Os gerentes de novos produtos e processos enfrentam um paradoxo: como tirar proveito de capacidades essenciais, sem ser prejudicado pelo seu lado disfuncional. No momento que o ambiente competitivo muda, ou acontece alguma 
'destruição criativa' (SCHUMPETER, 1942 apud HAGEDOORN, 1996) essa aparente fortaleza, representada pelas capacidades essenciais poderá se tornar uma inércia, derivada dos sistemas enraizados na organização, e totalmente adaptados a determinado paradigma. Esta "bagagem" acumulada pela empresa perde seu valor, caso não haja uma predisposição a uma rápida adaptação ou mesmo uma estruturação do mecanismo de aprendizado e geração de inovações constantes. Leonard-Barton (1998) faz referências a Tushman e Anderson (1986) afirmando que descontinuidades tecnológicas podem aprofundar ou destruir competências existentes dentro de uma indústria. Tais mudanças no ambiente externo ressoam dentro da organização, de modo que até mesmo "aparentemente a menor das inovações pode minar a utilidade do conhecimento profundamente enraizado"

A inovação pode ser proveniente da capacidade interna das firmas ou adquirida de fontes externas. As empresas que conseguem captar fontes externas de inovação trabalham dentro do conceito de inovação aberta. Segundo Chesbrough (2006), este tipo de geração de inovação refere-se a um modelo de gestão cuja função é o de capturar e criar valor com base em oportunidades localizadas dentro e fora da organização. Sua principal proposta é que as empresas façam uso de tecnologias e conhecimentos internos e externos para alcançar melhores resultados em seu processo de inovação. Destaca-se também a importância de se analisar o modo como tais tecnologias podem ser acessadas ou utilizadas para se gerar inovações. Neste sentido, ressalta-se a necessidade do estabelecimento de parcerias com diversos stakeholders no processo de inovação, tais como instituições de pesquisa, alianças estratégicas com outras empresas, ou a aquisição de propriedade intelectual.

Ainda quanto o gerenciamento da inovação, no modelo proposto por O'Reilly e Tushman (2004), os autores colocam a necessidade dos gerentes das empresas terem um foco duplo (ou ambidestro). Este olhar seria composto de um olhar para trás, atendendo aos produtos e processos do passado enquanto olham para frente, preparando para inovações que definirão seu futuro. É muito comum as organizações falharem no intuito de atingirem inovações radicais e ao mesmo tempo avanços constantes em seus negócios principais. Mas, segundo os autores, esta tarefa não é impossível para nenhuma organização. 


\section{ABORDAGEM METODOLÓGICA}

Optou-se por utilizar uma pesquisa de natureza qualitativa, através de entrevistas em profundidade com executivos da empresa Alfa, complementada pelo levantamento de dados documentais, tais como documentos internos e de sistemas informacionais. A empresa foi escolhida devido à sua tipicidade, por ser uma grande operadora do mercado de eventos brasileiro. Esta empresa estava participando das várias etapas da cadeia produtiva de eventos, incluindo o aluguel de espaços, a produção, montagem, catering e hospedagem de clientes. Na ocasião da pesquisa, um dos autores era funcionário possuindo um cargo gerencial, e por isso, contou com acesso a informações da organização, tanto de fontes documentais, quanto acesso aos demais executivos. No entanto, por motivos de confidencialidade da organização, optou-se por ocultar a identidade da mesma.

Quanto à escolha desta metodologia, ela baseia-se no fato de que se considerou que o tema de estudo era relevante, recente e pouco estudado no Brasil. Desta forma, não se pretendeu fazer generalizações, mas sim aprofundar o conhecimento de forma exploratória, dentro do contexto brasileiro e da empresa pesquisada.

O levantamento de informações, portanto, foi realizado pelo método qualitativo por meio de entrevistas em profundidade com 10 executivos, conforme descritos no quadro 1. O objetivo das entrevistas foi o de descobrir as características da inovação na organização, à luz do arcabouço teórico. Os entrevistados foram selecionados pelos critérios de tipicidade e acessibilidade (VERGARA, 2008). Inicialmente foi validado o cargo dos executivos, que deveriam ocupar posição de gestão, tendo sido entrevistados três diretores, quatro gerentes e três coordenadores. Optou-se por não revelar o nome dos entrevistados, embora no quadro 1 constem informações como sua idade, função e tempo trabalhado na organização. A idade, gênero, função foram selecionados aleatoriamente por critérios de acessibilidade. Complementando as entrevistas foi também utilizada a observação direta do ambiente organizacional, num período de dois anos, período durante o qual um dos realizadores deste estudo também fazia parte do quadro desta organização.

Segundo recomendações de Godoi e Mattos (2006), os pesquisadores optaram por não pré-definir o número de entrevistas. A quantidade de informantes, portanto, foi 
estipulada em função da saturação dos dados, com base na redundância e convergência dos relatos obtidos (LINCOLN; GUBA, 2002). Concluiu-se que o número de entrevistados proporcionou aos pesquisadores similaridades, diferenças e variedade de detalhes, sendo estas suficientes para a análise dos dados.

QUADRO 1 - DADOS DEMOGRÁFICOS DOS ENTREVISTADOS

\begin{tabular}{|c|c|c|c|c|c|}
\hline Número & 1 & 2 & 3 & 4 & 5 \\
\hline Referência & DIR1 & DIR2 & DIR3 & GER1 & GER2 \\
\hline Idade (anos) & 46 & 39 & 44 & 36 & 31 \\
\hline Função & $\begin{array}{ll}\text { Diretor } & \mathrm{de} \\
\text { núcleo } 1 & \end{array}$ & $\begin{array}{ll}\text { Diretor } & \mathrm{de} \\
\text { núcleo } 2 & \end{array}$ & $\begin{array}{ll}\text { Diretor } & \mathrm{de} \\
\text { núcleo } 3 & \end{array}$ & $\begin{array}{l}\text { Gerente de } \\
\text { Planejamento }\end{array}$ & $\begin{array}{ll}\text { Gerente } & \text { de } \\
\text { Produção } & \end{array}$ \\
\hline Sexo & Masculino & Masculino & Feminino & Feminino & Feminino \\
\hline $\begin{array}{l}\text { Tempo } \\
\text { trabalhado na } \\
\text { Organização }\end{array}$ & 22 anos & 10 anos & 1,5 anos & 11 anos & 11 anos \\
\hline Número & 6 & 7 & 8 & 9 & 10 \\
\hline Referência & GER3 & GER4 & COORD1 & COORD2 & COORD3 \\
\hline Idade (anos) & 49 & 38 & 27 & 28 & 29 \\
\hline Função & $\begin{array}{l}\text { Gerente de } \\
\text { Arquitetura }\end{array}$ & $\begin{array}{l}\text { Gerente de } \\
\text { Negócios }\end{array}$ & $\begin{array}{l}\text { Coordenadora } \\
\text { de Marketing }\end{array}$ & $\begin{array}{l}\text { Coordenadora } \\
\text { de Produção }\end{array}$ & $\begin{array}{l}\text { Coordenadora } \\
\text { de Produção }\end{array}$ \\
\hline Sexo & Masculino & Feminino & Feminino & Feminino & Feminino \\
\hline $\begin{array}{l}\text { Tempo na } \\
\text { Organização }\end{array}$ & 20 anos & 9 anos & 2 anos & 3,5 anos & 4 anos \\
\hline
\end{tabular}

Fonte: Elaborado pelos autores. Pesquisa de campo, 2013.

O registro das entrevistas foi apoiado em roteiros semiestruturados (CRESWELL, 2009) com anotações e observações de campo complementares à sua gravação. Seguindo as recomendações de Vergara (2009), os pesquisadores efetuaram pessoalmente as entrevistas em profundidade, gravando-as num tablet e realizando a transcrição integral dos relatos.

Para se analisar os perfis através das falas transcritas, foram identificadas as primeiras ideias relativas ao texto, pontos chaves, padrões e relações entre as características de seus relatos e a grade de análise. Confrontaram-se posteriormente os resultados com a teoria escolhida, formulando-se as conclusões deste estudo. Os pesquisadores complementaram esta análise com a extração de sentenças das falas dos entrevistados, visando exemplificar os perfis identificados. A análise de conteúdo utilizou apenas uma abordagem qualitativa e as falas obtidas por meio das entrevistas, analisadas pelo seu caráter descritivo da realidade (BARDIN, 2006). 


\section{ANÁLISE E DISCUSSÃO}

A Alfa, apesar de fazer parte de um grupo multinacional estava inserida no contexto de uma empresa de país emergente, deslocada da 'fronteira tecnológica internacional'.

Como constatado nas entrevistas, na Alfa no Brasil, o processo de acumulação de capacidades tecnológicas não foi muito diferente do da maioria das empresas do contexto de economias emergentes. Ela começou como uma empresa local, promotora e operadora de feiras de negócios no Rio de Janeiro, fundada em 1964 para ser uma montadora de stands de feiras, desenvolvendo seu conhecimento de forma prática e acumulando ao longo destes anos seu conhecimento basicamente de forma tácita. $\mathrm{O}$ foco, portanto, se deu na acumulação de capacidades tecnológicas em suas rotinas operacionais (LEONARD-BARTON, 1998).

Já sob gestão da empresa multinacional, desde 2012 a empresa iniciou um mapeamento dos processos de produção e organização de eventos, o que se evidenciou como uma iniciativa em prol do registro das informações em procedimentos e padrões e acumulação de capacidades tecnológicas em forma de ativos organizacionais, e não de forma tácita (LEONARD-BARTON, 1998), conforme relatou a Gerente de Planejamento (GER1).

Este registro de rotinas é o primeiro passo da acumulação de capacidades tecnológicas, como foi constatado ao se entrevistar os profissionais mais antigos da organização, como o gerente de arquitetura (GER3) e um dos diretores de núcleo (DIR1). Estes executivos de áreas-chave afirmaram veementemente que a "empresa sabia fazer eventos, mas não registrava muitas vezes os processos". Este ciclo de incorporação do conhecimento na Alfa parece ter se manifestado de forma truncada. As demandas de conhecimento e know-how apareceram ao longo de sua trajetória e de acordo com as necessidades de seus eventos. Algumas áreas como o departamento financeiro, o departamento comercial, a área de produção de eventos apresentava iniciativas de formalização e codificação de processos, seja em mapeamento de processos (na produção) ou pela implantação de sistemas técnico-físicos, como sistemas de registro de informações financeiro-contábeis, assim como sistemas de registro de 
histórico de clientes - CRM, implantada entre os anos 2013 e 2014, conforme constatado através da observação.

A capacidade de absorção de conhecimentos e know-how requer capacidade de aprendizado e desenvolvimento de habilidades para resolução de problemas e possui dois elementos importantes: a base de conhecimento prévio e a intensidade de esforço (COHEN; LEVINTHAL, 1990). O mapeamento e registro de processos organizacionais em 2012 foi complementado por outra dimensão do catch-up tecnológico, o treinamento e educação do quadro de gerentes da empresa, a partir de 2013. Este programa, promovido pela área de recursos humanos, foi estabelecido através da contratação de uma renomada instituição de ensino e treinamentos gerenciais em diversas disciplinas de todo quadro gerencial e diretoria.

Embora estas iniciativas tenham sido importantes para mudar o patamar de conhecimentos de seu quadro gerencial, outro fato que chamou a atenção dos pesquisadores foi a baixa integração de tecnologias licenciadas por outras filiais (ou países), ou mesmo projetos de transferência de know-how através da contratação de técnicos especializados. Esta migração de indivíduos de uma filial da organização (ou país) para outra, pode promover também a transferência de conhecimentos tácitos, elevando o nível de conhecimento prévio de uma organização.

Para determinar qual caminho de aquisição tecnológica a organização deverá trilhar, Christensen (2004) apresenta o dilema das empresas que devem decidir se irão ficar numa tecnologia estabelecida e trabalhar em pequenas mudanças incrementais ao longo do tempo, ou migrar para um novo patamar tecnológico, muito vezes inovando radicalmente. No caso da Alfa, a empresa optou por não se arriscar em sair das mudanças incrementais. Fagerberg (2005) cita o fato de que "as firmas normalmente inovam por uma necessidade de mercado" e partem de uma base de conhecimentos já pré-existentes na organização, daí a tendência da maioria das inovações serem incrementais, o que justificaria a posição da Alfa no Brasil, embora o mercado estivesse impulsionando para inovações mais estruturais e radicais para seus eventos, como sugerido por vários dos executivos ao tentarem explicar o decréscimo de visitantes às feiras que trazem pouca inovação.

Já Pavitt (1990) também elenca as características chave do processo de inovação tais como a colaboração entre departamentos, a incerteza, a natureza cumulativa do 
conhecimento, a diferenciação e especificidade. O autor explica que as empresas não escolhem serem especializadas ou de escopo aberto em sua estratégia de inovação, tampouco escolhem serem lideres ou seguidoras. Quem determina estas características são o mercado e o contexto das organizações. Segundo Teece, Pisano e Shuen (1994), as capacidades inovadoras são o conjunto de habilidades diferenciadas, ativos complementares e rotinas que proporcionem a base para vantagem competitiva sustentável em um negócio. Neste sentido os autores afirmam que as capacidades inovadoras só se convertem em vantagens competitivas se as rotinas, habilidades e ativos complementares forem difíceis de copiar. Quanto mais tácito for seu conhecimento produtivo, mais difícil será de copiar, convertendo-se numa vantagem competitiva. Isto poderia ser uma vantagem para a Alfa, que estava adquirindo grande parte de seu conhecimento de forma tácita, embora sua fraqueza se encontrasse na falta de um mecanismo formal de constante aperfeiçoamento de suas rotinas e incorporação deste conhecimento em rotinas organizacionais e sistemas físicos.

Ainda em relação à acumulação das capacidades tecnológicas, com base em Leonard-Barton (1998), as quatro dimensões na Alfa apresentaram-se da seguinte forma:

a) Os sistemas técnicos físicos - representados pelos equipamentos, maquinaria e sistemas baseados em tecnologia de informação e comunicação. No caso da Alfa havia sistemas de cobrança, orçamento e contabilidade financeira. Havia também na área comercial um sistema de CRM ("Sales Force”) e na área de viagens, um sistema de busca e aquisição de passagens aéreas. No lado da operação das feiras e eventos, o uso de equipamentos e automatização dos processos de credenciamento on-line de visitantes em geral aumentava sua visitação (produtividade) e eficiência na entrada para uma feira ou congresso. Uma maior profissionalização e menor risco de erro humano poderiam ser evidenciados com a utilização intensiva destes recursos.

b) Os conhecimento e qualificação das pessoas - representados pelo conhecimento tácito, as experiências, habilidades da equipe gerencial e técnica como produtores, gerentes, montadores de estandes e operadores. Este conhecimento é adquirido ao longo do tempo ou pode abranger a sua qualificação formal. Também denominada de "capital humano" da empresa. Os treinamentos, qualificação de pessoal e capacitação gerencial podem ser ativos intangíveis, mas altamente percebidos pelos 
clientes, no tocante a qualidade de atendimento e eficiência da gestão, incrementando a competitividade das firmas. Na Alfa havia uma equipe acima da média na comparação com outras empresas de eventos, mas ainda havia um desafio de comunicação, integração de pessoas e até de fomento a iniciativas de inovação na gestão e promoção dos eventos.

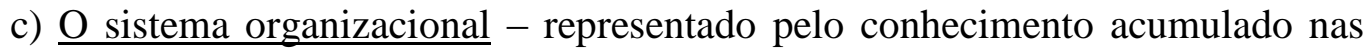
rotinas organizacionais e gerenciais das empresas, nos procedimentos, nas instruções, na documentação, na implantação de técnicas de gestão, nos processos e fluxos de produção de produtos e serviços e no know-how de certas atividades nas firmas. Muitas empresas convertem estes sistemas organizacionais em ativos importantes e por vezes difíceis de ser copiados, permeando o modo de fazer de uma empresa e tornando-se uma marca registrada. Em eventos esta dimensão pode trazer grande fidelização e confiabilidade de seus serviços. Em 2012 iniciou-se um mapeamento de processos da área de produção de eventos, que foi estendido para demais áreas chave como marketing, arquitetura e gerência de negócios. O esforço em se criar uma área de planejamento da empresa em 2013 indicava um movimento em direção à profissionalização das rotinas e processos. A alteração do desenho funcional em 2012 para um desenho matricial da organização também mostrou que fazia parte de um plano de formalização destes sistemas organizacionais. Em 2014, devido à crise registrada no setor e no país, houve um processo de reestruturação com demissão de seis gerentes, o que pode ter ocasionado perda do conhecimento tácito.

d) Os produtos e serviços - referem-se à parte mais tangível e visível da capacidade tecnológica, representada pelo conhecimento tácito das pessoas e da organização e os seus sistemas físicos e organizacionais; por exemplo, nas atividades de desenho, desenvolvimento, linha de produção, comercialização de produtos e serviços e atendimento. Esta integração de processos, apesar de às vezes se manter em forma de conhecimento tácito, ainda estava presente nos eventos da Alfa, que mantinha um diferencial em organização e fluidez de processos.

Bell e Figueiredo (2012) explicam que é possível, no entanto, começar com o mais baixo nível de capacidade tecnológica e evoluir para níveis bastante avançados, embora isto exija esforços em aprendizagem tecnológica para acelerar a acumulação de capacidades inovadoras. Portanto uma das tarefas mais importantes para empresas que 
operam em economias emergentes é a de acumular capacidade tecnológica a uma taxa mais rápida do que a das empresas que já operam na fronteira tecnológica internacional. Isto traz uma limitação ou um desafio maior à inovação.

Indicam-se alguns atalhos na aquisição de capacidades tecnológicas pela Alfa. Esta trajetória poderia ser a incorporação de conhecimentos e rotinas de 'segunda-mão' de sua matriz ou de outras divisões do grupo nas seguintes áreas: diversificação do modelo de negócios (OSTERWALDER; PIGNEUR, 2013), sustentabilidade (LAING; FROST, 2010), ou entrada em mercados de baixa renda por exemplo (ZILBER; SILVA, 2013; NERI, 2011).

- Diversificação no modelo de eventos - a exemplo de eventos que estavam sendo importados para a Alfa ("Omnivore" - evento de gastronomia; "Mondial de La Bière" - evento de degustação de cervejas artesanais), segundo informou na época o gerente de planejamento GER1, e corroborando com a inovação no modelo de negócios proposta por Osterwalder e Pigneur (2013);

- Aprofundar-se nas capacidades tecnológicas de montagem de estruturas temporárias - novos tipos de estandes mais econômicos, mais rápidos e mais ecológicos, e novas tecnologias de credenciamento;

- Inovação em comunicação - buscar melhores práticas de gestão de conteúdo em portais, e-mail marketing e redes sociais, visando incrementar e perpetuar a experiência do visitante e do expositor;

- Inovação para baixa renda - havia grande quantidade de necessidades não satisfeitas de serviços para grupos ditos de 'baixa renda'. Estas populações outrora excluídas no Brasil agora estavam fazendo parte da chamada 'classe média emergente'. A criação de eventos e prestação de serviços para 'baixa renda' poderia ser uma grande oportunidade de negócios não explorada, corroborando com o potencial deste público enunciado por Neri (2011) e Zilber e Silva (2013). A criação de eventos amigáveis, gratuitos, com mecanismos inteligentes para geração de negócios para a classe popular poderia ser uma vertente de inovação. Isto exigiria uma abordagem altamente inovadora e mudança de foco da empresa;

- Inovações em Sustentabilidade - A Alfa já seguia um programa global de responsabilidade ambiental idealizado por sua matriz com a intenção de minimizar o impacto de sua atividade no meio ambiente e corroborando com os estudos de Laing e 
Frost (2010), o programa 'Think Green' (Pense Verde) estava presente desde a organização e planejamento até a reutilização e gestão do lixo dos eventos realizados pela Alfa no Brasil, assim como a utilização de carpetes reciclados. Destaca-se a Estação de Tratamento de Água e Esgoto do Riocentro, capaz de tratar $340 \mathrm{~m}^{3}$ de esgoto por dia e o sistema de reuso de águas pluviais da HSBC Arena com quatro reservatórios de 160.000 mil litros, conforme informado pelo gerente de planejamento, GER1.

Segundo um dos diretores (DIR1) afirmou, a Alfa "ainda não consegue acompanhar plenamente a demanda dos visitantes por novidades e interatividade. Temos que investir muito nos eventos e às vezes isso não se paga". Isto evidenciou que suas competências essenciais de promoção de eventos que eram muito adequadas às demandas dos anos 1990, causaram uma 'inércia incumbente', uma resistência à mudanças internas da organização diante das mudanças do ambiente dos anos 2000. Esta descontinuidade foi percebida por visitantes e expositores presentes nas feiras e eventos da Alfa e manifestaram-se sob a forma de redução das taxas de visitação e de renovação de estandes, além de reclamações detectadas através de pesquisas de opinião aplicadas aos visitantes de suas feiras, tais como: "a feira não traz inovações nem lançamentos", ou "não voltarei a feira no ano que vem, pois não tive retorno ao meu investimento".

Cada vez mais, a sociedade demanda eventos que sejam plenamente interativos como afirmou o DIR1: “estes eventos são atualizados e integradores de soluções e pessoas como é o Campus Party que congrega milhares de profissionais de TI no Anhembi”. A Alfa estava tendo aí uma grande oportunidade de desenvolver eventos dentro destas características.

O gerenciamento bem-sucedido da inovação irá requerer uma capacidade de orquestrar grupos funcionais e de especialistas; o questionamento contínuo da adequação dos eventos a seus mercados, e a habilidades e a predisposição para visão de longo prazo na estratégia de inovação.

Apesar de a Alfa ser uma subsidiária da multinacional do ramo de eventos, não havia processos estabelecidos de transferência de conhecimento e introdução de knowhow de processos estrangeiros. Eram contratados novos indivíduos que tinham de buscar o conhecimento através da interação com outros indivíduos mais experientes da empresa. O processo de transmissão do conhecimento era informal, como constatado 
nas entrevistas e na falta de registro das rotinas. Perdia-se energia neste processo de transferência de conhecimento individual. Talvez a falta de um direcionamento estratégico e de uma política de inovação trouxesse esta cultura.

A Alfa, sobretudo, tinha a oportunidade de buscar a participação dos clientes nesses processos de "co-geração", o que poderia envolver trocas de informação através de formulários de pesquisas, canais de comunicação on-line e entrevistas presenciais, como focus groups com seus clientes e parceiros.

A inovação aberta, portanto, é um processo interdisciplinar que requer que peritos de diversas disciplinas estejam trabalhando em conjunto ao longo de um projeto. Por este motivo, estes projetos necessitam de uma liderança capaz de conduzir uma visão holística na criação de valor para o consumidor e ao mesmo tempo estar alinhado com as competências e estratégias das organizações envolvidas (CHESBROUGH, 2006). A Alfa, portanto, podia buscar as melhores práticas de eventos pelo Mundo, aproveitando suas características multinacionais. Um programa de visitação de feiras e eventos internacionais poderia ser criado, visando promover um maior intercâmbio entre as unidades do grupo. Os pesquisadores constataram que no momento a equipe do Brasil estava trabalhando muito isolada das demais unidades.

Mas, para Alfa se tornar ambidestra com foco no presente e no futuro, ela enfrentaria alguns desafios. O primeiro obviamente seria o de conviver com dois focos e duas realidades de negócios. O segundo desafio seria o de encontrar líderes que combinassem os atributos de "cortadores de custos rigorosos" e "empreendedores de pensamento livre", mantendo a objetividade necessária para dificultar as possíveis trocas, segundo O'Reilly e Tushman (2004). O terceiro desafio era o de formar uma equipe sênior com gerentes-executivos que tivessem a capacidade de compreender as diferentes necessidades dos dois focos de negócio. O quarto desafio seria o de enfrentar as possíveis resistências das equipes subordinadas e dos níveis superiores de uma organização (O'REILLY \& TUSHMAN, 2004). Este alinhamento deveria provir de uma visão clara e objetiva, e de um plano de comunicação adequados, partindo de um envolvimento das equipes mediado por fortes lideranças, ainda inexistentes na organização. 


\section{CONSIDERAÇÕES FINAIS}

Este artigo pode indicar quais dimensões das capacidades tecnológicas a Alfa deveria desenvolver. Outras empresas do setor de eventos também poderiam se utilizar deste trabalho para definirem planos ou projetos de inovação. Foram levantadas informações também sobre como as capacidades essenciais que poderiam afetar a inovação na empresa, alguns caminhos para realização do catch-up tecnológico e 'inovação aberta'. Por fim concluiu-se o trabalho com recomendações de possíveis novas fronteiras de inovação a serem exploradas pela organização. Apesar dos entrevistados abordarem estas iniciativas de mapeamento de processos e instalação de sistemas como uma medida de suma importância, a Alfa deveria se engajar num forte esforço de catch-up tecnológico. Como na maioria das empresas, este processo de assimilação tecnológica se inicia através de cópia ou de aquisição de tecnologias já desenvolvidas por outras firmas, este poderia ser um atalho indicado. Embora a literatura dê ênfase ao desenvolvimento de tecnologias inovadoras, nem todas as empresas podem ser pioneiras de novas descobertas para se tornarem competitivas, sobretudo no mercado de serviços. A aprendizagem organizacional é também uma importante capacidade a ser desenvolvida pela organização.

A partir das observações à luz da literatura recente em inovação, poderia se propor como próximos passos um aprofundamento ou mesmo comparação com outras organizadoras de eventos, já que este estudo não é conclusivo.

Para concluir como contribuição gerencial, espera-se que este artigo traga evidências de um caso real e também sugestões de possíveis novas fronteiras de inovação a serem exploradas por empresas de eventos ou organizações de serviços em contextos similares.

Como contribuição teórica, os autores esperam ter adicionado uma aplicação às teorias de inovação de Leonard-Barton (1998), no contexto do mercado de eventos brasileiro. 


\section{REFERÊNCIAS}

ABEOC. Brasil Sobe no Ranking de Eventos Internacionais. Disponível em: <http://www.abeoc.org.br/2012/05/brasil-sobe-no-ranking-de-eventosinternacionais/\#sthash.XOHj11sr.dpuf>. Acesso em: 28/04/2015.

BELL, M.; FIGUEIREDO, P. N. Building innovative capabilities in latecomer emerging market firms: some key issues. Innovative firms in emerging market countries. New York and London. 1. ed. Oxford: Oxford University Press, v. 1, p. 24$109,2012$.

BELL, M.; PAVITT, K. The development of technological capabilities. In: UL HAQUE, I. (ed.). Trade, Technology and International Competitiveness. Washington, DC: The World Bank, 1995.

Technological accumulation and industrial growth: contrasts between developed and developing countries. Technology, globalisation and economic performance, Cambridge University Press, p. 83-137, 1997.

CASTELLACCI, F. Technological paradigms, regimes and trajectories: manufacturing and service industries in a new taxonomy of sectoral patters of innovation. Research Policy, v. 37, p. 978-994, 2008.

CHESBROUGH, H. Open innovation: a new paradigm for understanding industrial innovation. Open innovation: Researching a new paradigm, p. 1-12, 2006.

CHRISTENSEN, C. M. O Dilema da Inovação. Makron Books: São Paulo, 2004.

COHEN, W. M.; LEVINTHAL, D. A. Absorptive capacity: A new perspective on learning and innovation. Administrative science quarterly, p. 128-152, 1990.

CRESWELL, J. W. Research design: qualitative, quantitative, and mixed methods approaches. Sage: California, 2009.

DOSI, G. Technical paradigms and technical trajectories, the determinants and directions of technical change and the transformation of the economy. Research Policy, v. 11, p. 147-162, 1982.

Sources, procedures, and microeconomic effects of innovation. Journal of Economic Literature. London, V. XXVI, p. 1120-1171, 1988.

Opportunities, incentives and collective patterns of technological change. The Economic Journal. v. 107, n. 444, p. 1530-1547, 1997.

FAGERBERG, J., MOWERY, D. C., NELSON, R. R. Innovation: a guide to the literature. In: FAGERBERG, J., MOWERY, D. C., NELSON, R. R. (Orgs.). The Oxford Handbook of Innovation. New York, Oxford University Press, 2005. 
GODOI, C. K.; MATTOS, P. L. C. L. Entrevista qualitativa: instrumento de pesquisa e evento dialógico. Pesquisa qualitativa em estudos organizacionais: paradigmas, estratégias e métodos. São Paulo: Saraiva, p. 301-323, 2006.

HAGEDOORN, J. Innovation and Entrepreneurship 'Schumpeter' Revisited. Industrial and Corporate Change, v. 5, n. 3, 1996.

HENDERSON, R. M.; CLARK, K. B. Architectural innovation: The reconfiguration of existing product technologies and the failure of established firms. Administrative Science Quarterly, p. 9-30, 1990.

ICCA. ICCA Statistics Report - Public Abstract, 2014. Disponível em: <www.iccaworld.com/dcps/doc.cfm?docid=1789>. Acesso em: 29/01/2014.

KIM, L. The Dynamics of Samsung's Technological Learning in Semiconductors. California Management Review, v. 39, n. 3, p. 86-100, 1997.

LAING, J.; FROST, W. How green was my festival: Exploring challenges and opportunities associated with staging green events. International Journal of Hospitality Management, v. 29, n. 2, p. 261-267, 2010.

LEONARD-BARTON, D. Nascentes do Saber: criando e sustentando as fontes de inovação. Rio de Janeiro: Editora Fundação Getulio Vargas: Rio de Janeiro, 1998.

LINCOLN, Y. S.; GUBA, E. G. Judging the quality of case study reports. In: HUBERMAN, A. M.; MILES, M. B. (Eds). The Qualitative Researchers' Companion. CA: Sage Publications, 2002

NERI, Marcelo Cortes. A nova classe média: o lado brilhante da base da pirâmide. São Paulo: Editora Saraiva, 2011.

O`REILLY, C. A.; TUSHMAN, M. L. The ambidextrous organization. Harvard business review, v. 82, n. 4, p. 74-83, 2004.

OSTERWALDER, A.; PIGNEUR, Y. Business model generation: inovação em modelos de negócios. Rio de Janeiro: Alta Books Editora, 2013.

PAVITT, K. "What we know about the strategic management of technology", California Management Review, spring, 1990.

PROPMARK. Setor de feiras movimenta R\$4 bilhões no Brasil. Disponível em: $<$ http://propmark.uol.com.br/mercado/42404:setor-de-feiras-movimenta-r-4-bilhoes-nobrasil>. Acesso em: 03/03/2015.

TEECE, D., PISANO, G., SHUEN, A. The dynamics capabilities and strategic management". In: Industrial and Corporate Change, v. 3, p. 537-556, 1994. 
TUSHMAN, M. L.; ANDERSON, P. Technological discontinuities and organizational environments. Administrative science quarterly, p. 439-465, 1986.

VERGARA, S. C. Métodos de coleta de dados no campo. São Paulo: Atlas, 2009.

UBRAFE. UNIÃO BRASILEIRA DOS PROMOTORES DE FEIRAS DE NEGÓCIO. Relatório 2015. Disponível em:

<http://www.ubrafe.org.br/ShowEXEMPLAR.asp?var_chavereg=806.>. Acesso em: 06/06/2015.

VON TUNZELMANN, N. Technology and Industrial Progress. The Foundations of Economic Growth. Cheltenham: Edward Elgar: Aldershot, 1996.

ZILBER, S. N.; SILVA, F. L. da. Investigação sobre a existência de inovações disruptivas das grandes empresas multinacionais para o mercado brasileiro de baixa renda. Produção, v. 23, n. 2, p. 283-296, 2013.

Recebido em: 29-07-2015

Aprovado em: 28-08-2015. 